\title{
AUDIOVISUAL TRANSLATION: ANALYSIS OF PHONIC TRANSFER IN CYRANO DE BERGERAC FILM \\ Ana $M^{a}$ Mallo Lapuerta \\ Universidad de Valladolid
}

\begin{abstract}
Regarding post-synchronization proper, one of the most interesting issues relates to voice transfer. To this purpose, we shall be highlighting voice-related meanings and features as well as its role in the utterance of sounds and words which in turn communicate, disclose and share emotions, feelings or moods. The study of voice production from the physiological point of view, together with its technical features like intensity, duration, timbre and pitch, is a key element in ascertaining how, from a scientific perspective, it is those qualities that are responsible for specific subjective perceptions in human beings. Knowing how any such vocal feature affects the transmission of several emotions can be very useful in film, since filmmakers and dubbing directors can thus select the right range of voices in order to convey specific feelings in both the source and the target texts.
\end{abstract}

KEY WORDS: Audiovisual Translation, Cyrano de Bergerac, Dubbing, Voice.

\section{RESUMEN}

La selección de voces en las versiones original y doblada de la película de Cyrano de Bergerac (Jean-Paul Rappeneau, 1990) es fundamental para lograr el éxito de la película. Una obra destinada al público mide sus efectos por la recepción del espectador. Para comprobar la impresión de las voces en el receptor meta, llevamos a cabo un análisis del trasvase fónico (no verbal) de las voces protagonistas del filme. Además, se ha realizado el análisis objetivo de la voz por medio de una novedosa herramienta de gran utilidad para el estudio de aspectos fonológicos: un sonograma. La evaluación de los resultados arroja interesantes aspectos a tener en cuenta en la Traducción Audiovisual para el doblaje.

PALABRAS CLAVE: Traducción audiovisual,Cyrano de Bergerac, doblaje, voces.

FECHA DE RECEPCIÓN: 13/04/2015

FECHA DE ACEPTACIÓN: 29/06/2015

PÁGINAS: $733-740$ 


\section{ANALYSIS OF PHONIC TRANSFER}

One of the most interesting problems in audiovisual translation —and more particularly in translation for dubbing purposes- is voice transfer. Let us briefly explain the treatment of voice in film and, more particularly, the handling of voice replacement in this very special case, where the protagonist of the French film production Cyrano de Bergerac, possesses a voice rich in pitches and nuances. To this end, we must first emphasize the role of human voice as a vehicle for the transmission of sounds and words, and how the latter are used to communicate, learn and share emotions, feelings and moods (Rodero: 2005).

As we all know, other sounds making up a film's composite track — the film score, noise and silences_ fulfill a specific role in the movie. Analysing how voice is produced from the physiological point of view, as well as an actor's voice features, intensity, duration, timbre and pitch height is critical in ascertaining that, from a scientific perspective, it is those traits that trigger off a given subjective perception in humans beings.

Knowing how every single vocal feature influences de transmission of several emotions is very useful in film, since both the filmmaker and the dubbing director may thus single out specific voices with the aim of conveying to audiences a given impression and suggesting a whole range of feelings.

In order to conduct our analysis of phonic transfer - a key component in the quality of post-synchronization-, we deemed it necessary to study the main characteristics (pitch, timbre and loudness) in the voices of both the original actor playing Cyrano in the French version and the corresponding voice actor in the Spanish dubbed version.

Main characteristics of the lead actor's voice in the original version:

- Pitch: deep, impressive, conveying power and self-confidence. It engages the audience. From the subjective point of view, it delivers credibility.

- Timbre: clear and warm. Timbre is a complex feature to trace down in a human voice: a clear timbre communicates self-assurance, naturalness, humbleness, truthfulness; and a warm timbre, unlike a cold one, communicates closeness and credibility.

- Loudness: variable. In slow-paced scenes, the voice's intensity is low and matching a range of moods like sadness, dejection, anger, selfconfidence, etc; by contrast, in fast-paced scenes, the intensity is high and matches excited moods.

Main characteristics of the dubbing actor's voice: 
- Pitch: deep, just like the voice of the original actor. Highly impressive from the acoustic point of view, it engages the audience. The voice actor's low pitch also conveys the impression of maturity.

- Timbre: clear and warm, it communicates, just like in the original performance, a sense of truthfulness, closeness and credibility.

- Loudness: variable, depending on individual scenes.

According to the Spanish version's dubbing director Camilo García, the character of Cyrano brings together the full range of technical and artistic nuances an actor can display. He is romantic, a dreamer and a poet, a man in love, a reliable companion, a charismatic thinker, etc., but also a person who feels thwarted by his physical (certainly not moral) ugliness. His is one of the most demanding stage roles, requiring moreover the ability to recite verse - a skill fallen into disuse among actors graduating from drama schools these days.

Regarding voice, which is the focus of our interest, Depardieu's is able to caress our ears when he becomes tender, but he can also sound harsh and aggressive when the action requires it, even though it always remains extremely elegant and adaptable. It is properly placed and regulated in the diaphragm , allowing him to speak at the highest speed and shift the tone in a split second, while its overall sound is at all times pleasant and presents accurate, smooth harmonics, without straining sound emission. Depardieu recreates every word - every syllable even — into some kind of credible, natural and personal melody of powerful resonance, as can be easily perceived. Camilo García, a voice actor who has dubbed Depardieu on numerous occasions, accurately follows the protagonist's performing style and intent, taking on a highly mimetic relationship to the original actor. García knows Depardieu very well; they are both the same age and share a similar vocal range, which has become deeper and more substantial with the passage of time. Camilo García has often lent his voice to such internationally acclaimed actors as Anthony Hopkins, Harrison Ford and Gene Hackman.

In order to perform an objective test of the vocal features of both actors, we shall resort to a spectrogram, a tridimensional graph that objectifies variations in sound or voice frequency on the basis of its intensity along a time sequence and is visually plotted on coordinate axes. On the horizontal axis the mean duration is represented in seconds, whereas the vertical axis represents frequency in a linear fashion as measured in hertzs $(\mathrm{Hz})$ or kilohertzs $(\mathrm{kHz})$. An individual's audible range oscillates between $20 \mathrm{~Hz}$ and 8,000 $\mathrm{Hz}$. On the upper part of the graph appear the high pitches, while the low ones are plotted at the bottom of the graph, respectively representing the highest and lowest frequencies. The intensity of sound —as measured in decibels $(\mathrm{dB})$ - shows in a more or less opaque presentation, depending on whether the voice's loudness is greater or smaller. 
Spectrograms are used for the study of sound in several disciplines whether it be music, singing or several kinds of phonological analyses - since they allow us to describe sounds and constitute a fundamental tool of acousticvocal analysis. In our particular case, it becomes possible to employ them in order to carry out a comparative analysis of original and voice actors.

Several aspects emerge from this type of study as well as very interesting conclusions from the vantage point of sound variables and voicerelated acoustic features.

Let us remember that the main concepts associated to sound variables are as follows:

- Loudness or intensity: an acoustic concept that vocally correlates with volume and which can be defined as the subglottic pressure measured in decibels $(\mathrm{dBs})$, that is to say, in cycles per second. Akin terms refer to volume (strong/weak), relative levels (medium), musical dynamics (forte, piano, etc.).

- Frequency or pitch: a quality that refers to the variables of the mechanical sound wave. It depends on the number of vibrations per second $(\mathrm{Hz})$. Synonyms analogous to this concept relate to pitch (low/high), relative levels (medium) and musical dynamics (notes and musical notations like flat or sharp symbols, etc.).

- Timbre: a subjective feature marking the difference between two sounds with the same frequency, intensity and duration -one which depends on the combination of harmonics accompanying the fundamental pitch. Voice-related concepts that are involved in timbre are: harmonics and resonance — purely acoustic — and their non-harmonic characteristics (opaque, brilliant, etc.).

- Duration: characteristics that are not associated to the sound wave itself and instead relates to the permanence time of the sound stimulus, which depends on time measurement. Concurrent synonymsis this context is: long/short, medium, speech rate, number of syllables, etc. It is directed related to rhythm and can be defined as the sequence of hearing stimuli that follow a series of fixed periodical rules. Rhythm is in any case a factor to be borne in mind in our analysis, since it is an expressive issue. It closely relies on auditory stimuli, but also on pauses, that is to say, the absence of stimuli or silence. A slow rhythm entails long pauses, while a quick one involves short pauses.

In order to provide a more accurate voice description, we next show a spectrograph of a phrase pronounced by the original actor (see the upper section) and the corresponding utterance by the Spanish voice actor (see the lower section). 
2. SPECTROGRAPH: GÉRARD DEPARDIEU/ CAMILO GARCÍA

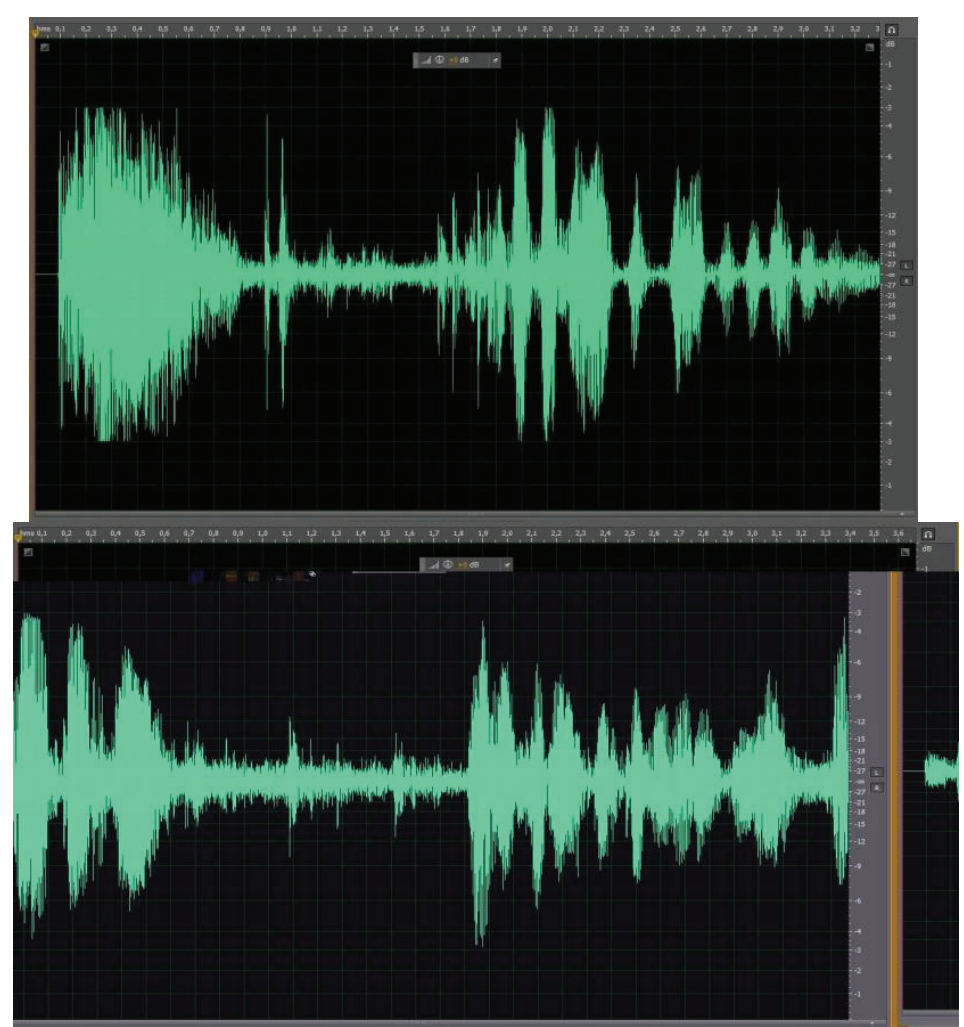

OV.:Tournez!Dites-moi pourquoi vous regardez, mon nez?

DV: ¡Me cargáis! ¿Puedo saber por qué mi nariz miráis?

From the point of view of sound variables, we may reach a number of different conclusions. The first part of the spectrograph, which as we may observe lasts for about a second (horizontal axis), corresponds to the first part of the phrase:

- Tournez! - iMe cargáis!

In French, the opacity of the phrase is greater than in Spanish, due to the fact that the word in the original version possesses a greater intensity. Moreover we may notice that there is no cut, as indeed happens with the corresponding Spanish chunk, which can be attributed to phonetic reasons, since in Spanish consonantal sounds included in the phrase me cargaiis, are silent, and the $/ \mathrm{k} /$, being occlusive, involves a break along the sound chain, 
giving way to the emergence of the open vowel "a". Since "g" is likewise voiced and open, it gives way to the "i" vocalic sound.

In the Spanish phrase, the opacity is lesser, which means a lower resonance, that is to say, a vocal placement that is both forward and open. Regarding the contribution of consonants, these are mirrored in the spectrograph according to their highest or deepest pitch. The "s" sounds being naturally high-pitched, they make for a higher tone altogether; while the Spanish "b", voiced and occlusive provokes a break and fosters intensity and resonance in the facial mask, which in turn explains why the spectrograph is broader.

The " $P$ " right at the beginning of the French phrase does not feature on the spectrograph, since it is both occlusive and voiceless, so that it simply constitutes the entry point for voiced sounds following as a result of pronouncing the word "-ourne-". The absence of breaks along the sound chain is due to the fact that the ensuing consonants are not voiceless - a phenomenon that is reflected on the spectrograph. Having said that, the pronunciation of the " $t$ " sound provides great power to the utterance force of the remaining vowels and consonants and accounts for the spectrograph being intense and mirroring the actor's anger —a resource meant to capture the attention of the viewer. Between seconds 1 and 1.9 there takes place what in phonological terms is called an "artefact", that is to say noises or sounds that interfere with the human voice. The second half of the phrase also highlights a number of interesting facts:

- Dites-moi pourquoi vous regardez. mon nez? - ¿Puedo saber porqué mi nariz miráis? ("May I ask you why to are staring at my nose?")

In the dubbing actor's speech, the full stress in the spectrograph falls on the pronunciation of the verb ending -áis. The consonantal sounds " $p$ " and " $\mathrm{k}$ " are voiceless and high-pitched, so that the spectrograph becomes larger and loudness increases. The " $\mathrm{m}$ " is both nasal and voiced, the " $\mathrm{n}$ " combines with the previous consonant and the vocalic sound " $i$ " vowel is partly made nasal. The consonantal sound "s", on the other hand, increases the wavelength, since there are more harmonics on the high-pitched part.

Regarding the voice features of either of the two actors as reflected on the spectrograph, Depardieu's possesses a somewhat lower pitch than Camilo García's (which can nevertheless be termed equally as deep). In acoustic terms, we may state that the dubbing actor's voice is clearer and possesses greater brilliance than the original actor's. As we saw before, a clear, brilliant timbre conveys truthfulness, calm, vivacity, humbleness, courage, honour, pride, passion, etc. However a harsh timber echoes an evil mind, lying, fear, distance, etc. 
The original actor's pace of speech is more variable and conveys intentionality more clearly; however, the voice actor's performance is endowed with a more linear rhythm, and maintains the same intensity throughout the full speech (with the exception of the phrase me cargáis), so that we may safely posit that Depardieu's performance is more expressive. We may reach the conclusion that the original actor being a "pshysical" performer, he tends to rely more on image and gesture to produce his discourse, while in voice-only acting, performance hinges solely on voice, so that if we did not see the images, CamiloGarcía's performance would perhaps be more eloquent.

In conclusion, we may say that in the case of Cyrano, spectrographic analysis confirms that the dubbing actor's voice suggested a greater truthfulness and sense of pride than that of the original voice in Rappeneau's film.

The spectrograph, in short, reveals that the dubbing actor's voice is more clear and possesses more brilliance than the original actor's. As we know through our analysis of voice properties, a clear and brilliant timbre conveys such qualities as truthfulness, calm, humbleness, vivacity, passion, etc.

The test likewise discloses that the dubbing actor's voice possesses a higher pitch and is more intelligible than the original actor's. Interestingly, the latter perception focuses on phonological, not linguistic reasons, which means that the Spanish voice actor would be better understood in whichever target language, since his articulation is clear and precise.

In film translation, voice is a fundamental link in providing the cinematic text with meaning, yet it is also a problem when it comes down to effecting the soundtrack transfer from one version to the other. The combination of picture and sound, a critical factor in producing the film's translation and lip-sync adjustment, makes it possible to accomplish quality standards in the target version, notwithstanding the possibility that some chunks may fall below such quality expectations, as happens when viewers become consciously aware that they are watching a "manipulated" film or that the original voice is being appropriated into a language other than its own.

In summary, non-verbal communication plays an indispensable role in communication at large. While it is often ignored, it also tends to be taken into account more and more in present-day research work. In our case, it has allowed us to gain a more accurate and comprehensive insight into dubbingtargeted filmtranslation. 


\section{BIBLIOGRAPHY}

Berry, C. (2006). La vozy el actor. Barcelona, Alba.

Ezpeleta, P. (2007). Teatro y traducción: aproximación interdisciplinaria desde la obra de Shakespeare. Madrid, Cátedra.

Gimferrer, P. (2012). Cine y literatura. Barcelona, Austral.

Key, M. R. (1982). Nonverbal Communication Today: Current Research. TheHague, Mouton.

Kohan, Silvia Adela (2004). Las estrategias de la voz. Cómo escoger la voz adecuada para que el relato fluya, tenga unidad y atrape al lector. Barcelona, Alba.

Poyatos, F. (2002). Nonverbal Communicationacross Disciplines. Vol. II: Paralanguage, kinesics, silence, personal and environmental interaction. Amsterdam, John Benjamins.

Rodero Antón, Emma. (2005). Producción radiofónica. Madrid, Cátedra.

Rodríguez Bravo, Ángel (1998). La dimensión sonora del lenguaje audiovisual. Barcelona, Paidós.

Suárez, Alfonso S. (2008).Voces en imágenes. Asturias, Verité de Cinematografía. 